\title{
Controlled Release Behavior of Prodrugs Based on the Biodegradable Poly(L-glutamic acid) Microspheres
}

\author{
Kong Soo Kim, Tae Kyoung Kim, and Neil B. Graham* \\ Department of Chemical Engineering, Chungbuk University, \\ Cheongju 361-763, Chungbuk, Korea \\ * Department of Pure \& Applied Chemistry, University of Strathclyde \\ 295, Cathedral Street, Glasgow, G1 IXL, Scotland, U.K.
}

(Received November 9, 1998)

\begin{abstract}
Poly(L-glutamic acid) microspheres (PLGM) were obtained from hydrolysis of poly( $\gamma$-benzyl-L-glutamate) microspheres prepared by the precipitation polymerization in polystyrene solution. The degradation behavior of PLGM was investigated, and were led to the polymer prodrugs such as PLGM-5-FU and PLGM-Glc-5-FU conjugated 1,2-dihydroxy methyl-5-fluorouracil (DHM-5-FU), or D-glucosamine-5-fluorouracil (Glc-5-FU) on PLGM. The release behaviors of 5-FU derivatives from the prodrugs were investigated in vitro, and antitumor activities were tested against Sarcoma-180 ascites in vivo. Drug release rate from PLGM-Glc-FU was relatively rapid and higher antitumor activity than from PLGM-5-FU.

KEY WORDS Poly(amino acid) / Microsphere / Poly( $\gamma$-benzyl-L-glutamate) / Poly(L-glutamic acid) / Polymer Prodrug/ 5-Fluorouracil / Antitumor Activity /
\end{abstract}

The controlled release systems designed with a biodegradable poly(amino acid)s are desirable because they do not need to be restricted when drug delivery is complete. Poly(glutamic acid) microspheres have the application as a biodegradable drug carrier having reactive carboxyl groups, which is able to attach drugs and targeting moieties.

Poly $(\alpha$-amino acid)s have a potential for biodegradable medical applications ${ }^{1-3}$ such as temporary artificial skin substrates, polymer carriers for protein conjugates and drug delivery systems. Especially, water soluble poly $(\alpha-$ amino acid)s are typical biodegradable polymers, and thus these controlled release systems after the distinct advantage such that no residual polymer remains following drug release or polymer degradation.

In general, poly $(\alpha$-amino acid) microspheres can be prepared by solvent evaporation method $^{4}$ but these are large particles of micro size. Kim and $\mathrm{Graham}^{5}$ have reported the preparation of poly( $\gamma$-benzyl-L-glutamate) $(\mathrm{P}(\gamma-\mathrm{BLG}))$ microspheres by the precipitation polymerization.

Many anticancer drugs are entrapped in microspheres and show rapid release from the microspheres. Chemical modification of drug materials in order to develop adequate physicochemical properties can be a promising approach to improving the drug's incorporation efficiency and release profiles. The derivatives of 5-fluorouracil (5-FU) as prodrugs have also been developed in order to reduce the toxic side effects and minimize delivery problem. ${ }^{6-8}$ Various types of the prodrugs conjugated antitumor agents polymer matrices were synthesized,,$^{9-11}$ and the antitumor activity of synthetic polymeric drugs having 5-FU, and physically incorporated polymers has been investigated. ${ }^{12-14}$

In previous study, ${ }^{5} \mathrm{P}(\gamma$-BLG $)$ microspheres were prepared by precipitation polymerization method which can obtain at high yield and control the particle size. In this study, We report about in vitro degradation behaviors of $\mathrm{P}(\gamma-\mathrm{BLG})$ microspheres. In order to achieve the active targeting of macromolecule drug conjugated, several prodrugs conjugated 1,2-dihydroxy methyl-5fluorouracil (DHM-5-FU), or D-glucosamine-5-fluorouracil (Glc-5-FU) on the debenzylated P( $\gamma$-BLG) microspheres obtained by previously reported method ${ }^{15,16}$ were prepared. The controlled release behaviors of the prodrugs were studied in vitro and the antitumor activity was tested against Sarcoma-180 ascites in vivo.

\section{EXPERIMENTAL}

\section{Materials}

PLGM were obtained from hydrolysis of $\mathrm{P}(\gamma-\mathrm{BLG})$ microspheres prepared by previously reported method. ${ }^{5}$ 5-FU and D-glucosamine hydrochloride $(\mathrm{Glc}-\mathrm{HCl})$ were obtained Aldrich Chem. Co. Papain was purchased from Sigma Chem. Co. and used without further recrystallization. Organic solvents and other chemicals used reagent grade.

\section{Hydrolysis of $P(\gamma-B L G)$ Microspheres}

Hydrolysis of the microspheres was performed by mixed solution of water-methanol-2-propanol (1:2:2, $\mathrm{v} / \mathrm{v} \%$ ) containing $0.5 \mathrm{wt} \% \mathrm{KOH}$ at $25^{\circ} \mathrm{C}$ for $16 \mathrm{~h}$. The product was precipitated in diethyl ether. The debenzylated microspheres were filtered, washed with diethyl ether and dried at room temperature under vacuum.

\section{In Vitro Degradation Test}

In order to estimate the main chain amide cleavage of $\mathrm{P}(\gamma-\mathrm{BLG})$ microspheres was studied in vitro. The microspheres were soaked in $10 \mathrm{~mL}$ of $0.1 \mathrm{M}$ phosphate buffer solution ( $\mathrm{pH} 7.4$ ) contained $0.1 \mathrm{mg} \mathrm{mL}^{-1}$ Papain. The reaction mixtures were incubated on a shaking bath maintained at $37^{\circ} \mathrm{C}$ for various soaking time. At various time points the microspheres were removed, washed with distilled water and dried at room temperature under vacuum.

In order to investigate the degradation behavior of the microspheres, the change of molecular weight was determined by gel permeation chromatography (GPC, 
Waters 750). The instrument consisted of two columns (HSG-50S). The sample solution in $N, N$-dimethylformamide (DMF) was eluted at a flow rate of $1.0 \mathrm{~mL} \mathrm{~min}^{-1}$ and the columns were calibrated by using polystyrene standard.

\section{Synthesis of the Prodrugs}

DHM-5-FU and GPC-5-FU were synthesized by previously reported method. ${ }^{15,16}$ DHM-5-FU (0.83 g, $5 \mathrm{mmol})$ or Glc-5-FU (1.74 g, $5 \mathrm{mmol})$ added to the $0.15 \mathrm{~g}$ $(5 \mathrm{mmol})$ of PLGM suspended in $10 \mathrm{~mL}$ DMF, respectively and then $1.03 \mathrm{~g}(5 \mathrm{mmol})$ of dicyclohexyl-carbodiimide (DCC) was added. The reaction mixture was stirred at room temperature for $12 \mathrm{~h}$, and then washed acetone, and dried at room temperature under vacuum.

\section{Determination of Drug Release Behavior}

In order to determine amount of conjugated 5-FU on the polymer prodrugs, hydrolysis of the prodrugs was carried out in $3 \mathrm{~N}-\mathrm{NaOH}$ aqueous solution at $60^{\circ} \mathrm{C}$ for $24 \mathrm{~h}$ and 5-FU content was determined at $265 \mathrm{~nm}$, respectively by UV/Vis Spectrophotometry (Cecil, Model 5500).

Weighed amount of the prodrugs in the dissolution flask attached mechanical stirrer were suspended in $0.1 \mathrm{M}$ phosphate buffer solution ( $\mathrm{pH}$ 7.4). The drug release test was carried out in cellulose tubing (dialysis "SACKS", Sigma, No. 250-7U) containing polymer prodrugs and buffer solution. The dissolution flask was immersed in a water bath maintained at $37^{\circ} \mathrm{C}$ and stirred at $80 \mathrm{rpm}$. At fixed time intervals, an aliquot of the solution was withdrawn an appropriate volume of fresh medium was added. The amount of drug released through cellulose tubing from these polymer prodrugs was determined by $\mathrm{UV} / \mathrm{V}$ is spectrophotometry.

\section{Evaluation of Antitumor Activities}

The antitumor activities were tested in vivo against Sarcoma-180 ascites in female mice. The mice weighing $25 \pm 2 \mathrm{~g}$ were used. Ten mice for each group, either tested or control, were implanted with $1 \times 10^{6}$ cells of Sarcoma- 180 ascites. Polymer prodrugs to be tested were daily administrated by intraperitoneal injection for five days, starting $24 \mathrm{~h}$ after transplanation.

The antitumor activities were evaluated by the ratio of prolongation of life, $T / C(\%)$, which means the ratio of medium survival of treated mice $(T)$ to that of control $(C)$.

\section{RESULTS AND DISCUSSION}

In this study, PLGM used which is prepared by debenzylation of $\mathrm{P}(\gamma-\mathrm{BLG})$ microspheres which is synthesized by precipitation polymerization in polystyrene solution. Particle size of selected microspheres was distributed in the region of $0.75-1.20 \mu \mathrm{m}$ and number average molecular weight of $2.7 \times 10^{4}$.

The expected debenzylation was indicated by the disappearance of the ${ }^{1} \mathrm{H}$ NMR (dimethyl sulfoxide (DMSO)- $d_{6}$ ) peak at $7.3 \mathrm{ppm}$ which is assigned to aromatic ring and at $5.05 \mathrm{ppm}$ while is assigned to benzyl $\mathrm{CH}_{2}$ after hydrolysis. From the NMR spectra, it was

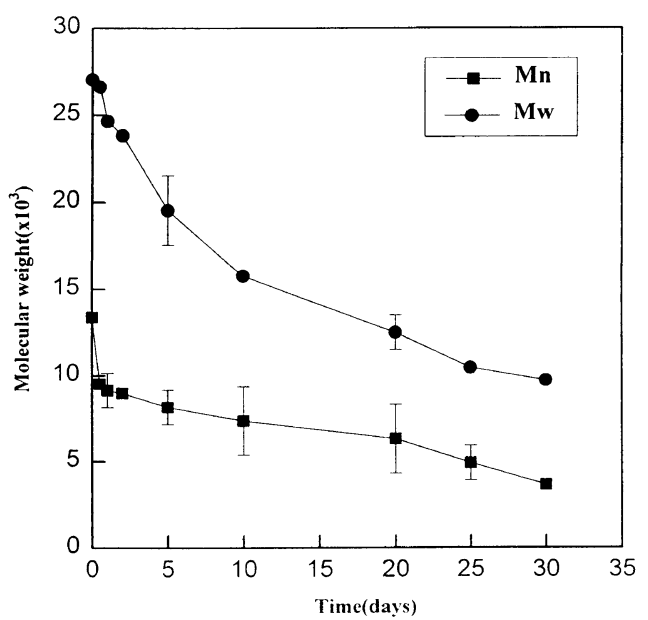

Figure 1. Degradation behavior of poly(L-glutamic acid) microspheres in enzymatic solution of papain $(0.1 \mathrm{~mL} / 1 \mathrm{~mL})$ at $37^{\circ} \mathrm{C}$.

confirmed that the debenzylation could be performed almost perfectively. The degradation of PLGM in the enzymatic solution of papain characterized in terms of molecular weight distribution GPC technique. From GPC chromatograms of PLGM incubated in the enzymatic solution of papain $(\mathrm{pH} 7.4)$ at $37^{\circ} \mathrm{C}$, it could be seen a distinct shift in the GPC peak to higher elution times, corresponding to a progressive decrease in the molecular weight of PLGM.

GPC studies showed that the degradation of PLGM in vitro in buffer solution of $\mathrm{pH} 7.4$, resulted in progressive decrease in the molecular weight distribution of the polymer overtime. Figure 1 shows that the molecular weight of PLGM decreased significantly with time. After 30 days in immersed medium the number average molecular weight $\left(M_{n}\right)$ of PLGM decreased from $1.34 \times$ $10^{4}$ to $3.65 \times 10^{3}$ daltons, and also the weight average molecular weight $\left(M_{w}\right)$ of that decreased from $2.7 \times 10^{4}$ to $9.3 \times 10^{3}$.

The polymer prodrugs were prepared by conjugation of antitumor agent based on the PLGM obtained by debenzylation of $\mathrm{P}(\gamma-\mathrm{BLG})$ microspheres. The preparation steps of the prodrugs is represented in Scheme 1.

The polymer prodrugs based on the PLGM were prepared from the conjugation of DHM-5-FU or Glc-5FU with DCC in DMF solution. Morphology of the prodrugs based on PLGM is shown in Figure 2. The particles are spherical but are not uniform shape and an average particle size is $1.0 \mu \mathrm{m}$.

The characteristic absorption peaks of PLGM-5-FU and PLGM-Glc-FU appeared at $262 \mathrm{~nm}, 263 \mathrm{~nm}$, respectively. The polymer prodrugs containing 5-FU derivatives were hydrolyzed by treatment with $3 N-\mathrm{NaOH}$ aqueous solution, and then an amount of drug bound in the prodrugs was determined by UV/Vis measurement and an amount of bound drug in the prodrugs was about $10.7-14.8 \%(\mathrm{w} / \mathrm{w})$. The release behavior of 5 -FU derivatives from the polymer prodrugs was investigated in vitro at $37^{\circ} \mathrm{C}$ in phosphate buffer solution of $\mathrm{pH} 7.4$. The swelling and biodegradability of the polymer prodrugs might be a critical factor in the drug release. Figure 3 shows the drug release behaviors from the prodrugs initially containing $14.8 \%(\mathrm{w} / \mathrm{w})$ of drug. The drug release profile is different from diffusion-controlled 
<smiles>O=c1c(F)cn(CO)c(=O)n1CO</smiles>

1-2+ Bis hydroxymethyl) $5-\mathrm{FU}$

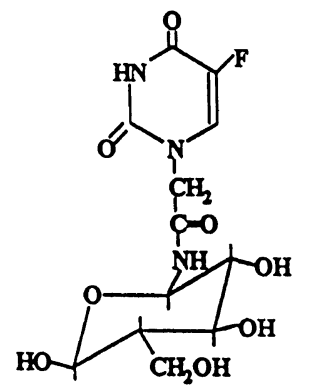

D-Gucosamine-5-FU
PLGM<smiles>CC(C)(CO)COC(=O)C(CCC(=O)O)NC(C)(C)C</smiles>

PLGM- 5- FU<smiles>O=c1[nH]cc(F)c(=O)[nH]1</smiles><smiles>CC</smiles>

Scheme 1. Preparation of PLGA microsphere conjugated 5-Fu derivatives.

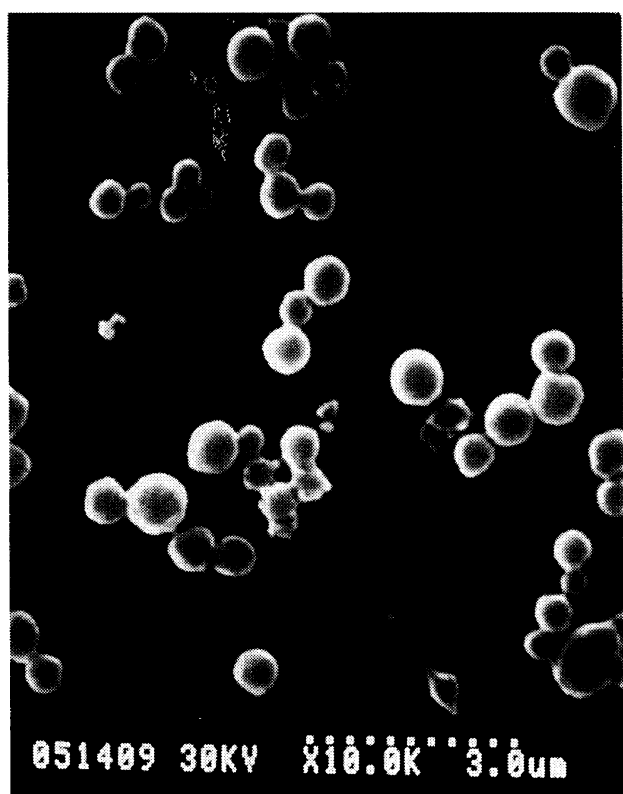

Figure 2. Scanning electron micrographs of PLGM prodrug prepared by precipitation polymerization.

and the drug release rate from PLGM-Glc-5-FU was comparatively faster than that from PLGM-5-FU. The release rate of 5-FU from PLGM-5-FU was only 20 $22 \%$ and that of Glc-5-FU from PLGM-Glc-5-FU was $45 \%$ for a week. From this drug release behaviors, it could be explained that the drug release will be sustained for long period.

This result indicates that the hydrolytic rate for amide bond in the main chain is much slower than that for the pendant ester bonds. Since it takes long period to cleave for 5-FU having really antitumor activity from monomer prodrugs such as DHM-5-FU Glc-5-FU, it is expected that the release rate of monomer prodrugs toward 5- FU will affect in vivo.

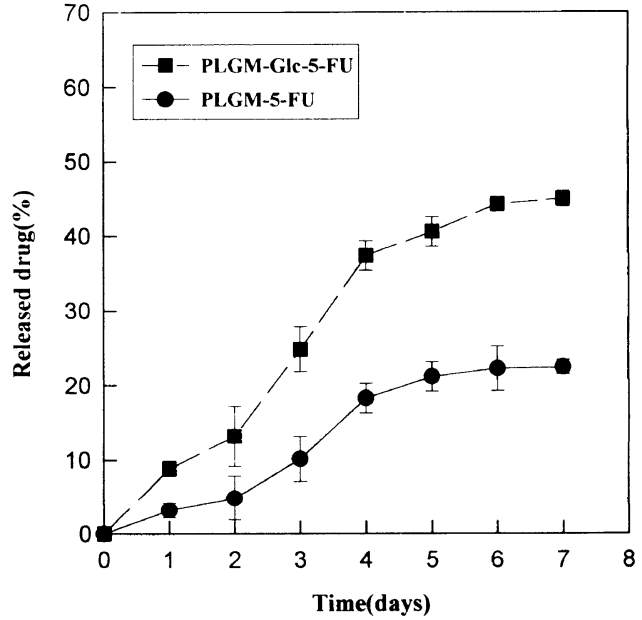

Figure 3. Release profiles of drug from the prodrugs in phosphate buffer solution $(\mathrm{pH} 7.4)$ at $37^{\circ} \mathrm{C}$.

Table I shows antitumor activities of the prodrugs against Sarcoma-180 ascites in vivo. Antitumor activities of 5-FU were decreased with increasing of dose in the range of $10-50 \mathrm{mg} \mathrm{kg}^{-1}$ for a day. But these polymer prodrugs showed relatively good antitumor effect despite much dose of $100-400 \mathrm{mg} \mathrm{kg}^{-1}$. It is found that PLGM$5-\mathrm{FU}$ showed a poor effect $(T / C: 110.0-125.0 \%)$, and PLGM-Glc-5-FU showed relatively higher effect $(T / C$ : 113.0-137.5). PLGM-5-FU showed the maximum effect $(T / C: 125 \%)$ at the dose of $300 \mathrm{mg} \mathrm{kg}^{-1}$ and PLGMGlc-5-FU showed the maximum effect $(T / C: 137.5 \%)$ at $200 \mathrm{mg} \mathrm{kg}^{-1}$. These polymer prodrugs showed PLGMGlc-5-FU showed relatively good antitumor effect despite the high dose of $100-400 \mathrm{mg} \mathrm{kg}^{-1}$. The higher activity of PLGM-Glc-5-FU may be attributable to their rapid release rate of the drug from the microspheres. From this results, it was expected that polymer prodrug containing D-glucosamine is biocompatible and not inhibit 
Table I. Antitumor activities of polymer prodrugs against Sarcoma-180 ascites in vivo

\begin{tabular}{|c|c|c|c|c|}
\hline \multirow{2}{*}{ Group } & Dose $^{a}$ & Amount of $5-\mathrm{Fu}$ & MST & $T / C^{\mathbf{b}}$ \\
\hline & $\mathrm{mg} \mathrm{kg}^{-1}$ & $\mathrm{mg}$ & day & $\%$ \\
\hline Control & Saline & 一 & 20.0 & 100.0 \\
\hline \multirow{3}{*}{$5-\mathrm{FU}$} & 10 & 10 & 26.0 & 130.0 \\
\hline & 30 & 30 & 25.0 & 125.0 \\
\hline & 50 & 50 & 24.3 & 121.5 \\
\hline \multirow{4}{*}{ PLGM-5-FU } & 100 & 14.78 & 22.0 & 110.0 \\
\hline & 200 & 29.56 & 23.6 & 118.0 \\
\hline & 300 & 44.34 & 25.0 & 125.0 \\
\hline & 400 & 59.12 & 24.1 & 120.5 \\
\hline \multirow{4}{*}{ PLGM-Glc-5-GU } & 100 & 10.67 & 24.0 & 120.0 \\
\hline & 200 & 21.34 & 27.5 & 137.5 \\
\hline & 300 & 32.01 & 26.3 & 131.5 \\
\hline & 400 & 42.68 & 22.6 & 113.0 \\
\hline
\end{tabular}

Note: Inoculated cells. $1.0 \times 10^{5} / 0.2 \mathrm{~mL}$, i.p. injection.

${ }^{a}$ The mice were administrated by intraperitoneal (i.p.) injection for four days. ${ }^{\mathrm{b}} T / C$ was ratio of median survival of treated mice $(T)$ to that of controlled mice $(C)$.

activity of drug.

\section{CONCLUSION}

The combination of chemical modification and polymeric carrier devices seems to be a promising means to control the in vivo fate and increase the therapeutic efficiency of anticancer agents. In order to accomplish this purpose, the degradation of PLGM derived from debenzylation of $\mathrm{P}(\gamma-\mathrm{BLG})$ microspheres in the enzymatic solution of papain was characterized, and the prodrugs were prepared by conjugation of DHM-5-FU of Glc-5-FU based on PLGM. The release of Glc-5FU from PLGM-Glc-5-FU was more rapid than that of 5-FU from PLGM-5-FU in vitro. From in vivo test against Sarcoma-180 ascites tumor-bearing mice, it was found that PLGM-Glc-5-FU containing D-glucosamine showed relatively good antitumor activity. It is suggested that PLGM-Glc-5-FU exhibit less toxicity and higher activity more than PLGM-5-FU, can be used for effective cancer chemotherapy.

Acknowledgments. This paper was supported by the cooperative research program from the Korean Research Foundation, 1996.

\section{REFERENCES}

1. M. Shahar, H. Meshulam, and S. Margel, J. Polym. Sci., Polym. Chem. Ed., 24, 203 (1986).

2. C. M. Klech and X. Li, J. Pharm. Sci., 79, 999 (1990).

3. T. Hayashi, E. Nakanishi, Y. Iizukn, M. Oya, and M. Iwatsuki, Eur. Polym. J., 30, 1065 (1994)

4. H, Ihara, T. Yoshinaga, Y. Motozato, and C. Hirayama, Polym J., 17, 1301 (1985).

5. K. S. Kim and N. B. Graham, Polym. J., 31, 809 (1999).

6. S. Ozaki, I. Ike, H. Mizuno, K. Ishikawa, and H. Mori, Bull. Chem. Soc. (Japan), 50, 2406 (1975).

7. P. P. Umrigar, S. Ohashi, and G. B. Butler, J. Polym. Sci., Polym. Ed., 17, 351 (1979)

8. T. Ouchi, H. Yuyama, and O. Vogl, Makromol. Chem. Rapid Commun., 6, 815 (1985).

9. S. Poul and B. Rang, J. Appl. Polym. Sci., 26, 3927 (1981).

10. G. Levin and H. N. Nae, J. Appl. Polym. Chem. Ed., 23, 981 (1985).

11. H. Endoh, T. Kawaguchi, T. Seki, T. Hasegawa, and K. Jumi, Chem. Pharm. Bull., 39, 458 (1991).

12. T. Kawaguchi, Y. Suzuki, Y. Nakahara, N. Nambu, and T. Nagai, Chem. Pharm. Bull., 33, 301 (1985).

13. S. Ozaki, T. Nagase, H. Tamai, H. Mori, A. Hoshi, and M. Ligo, Chem. Pharm. Bull., 35, 3894(1987).

14. T. Ouchi, H. Kobayashi, and T. Banba, Br. Polym. J., 23, 221 (1990).

15. M. Tada, Bull. Chem. Soc. Jpn., 48, 3429 (1975)

16. K. S. Kim, S. H. Cho, and J. K. Kang, Polymer (Korea), 18, 877 (1995).

17. G. Holzwarth and P. Doty, J. Am . Chem. Sci., 81, 218 (1965) 